\title{
Normas de Alerta e Valência para 908 Palavras da Língua Portuguesa ${ }^{1}$
}

\author{
Nelson Rocha de Oliveira ${ }^{2}$ \\ Faculdades Integradas da União Educacional do Planalto Central \\ Gerson Américo Janczura \\ Goiara Mendonça de Castilho \\ Universidade de Brasilia
}

\begin{abstract}
RESUMO - Normas de valência e alerta para 908 palavras foram coletadas utilizando-se a escala de julgamento SAM (SelfAssessment Manikin). Participaram do estudo 4.359 estudantes universitários oriundos de quatro universidades. Os resultados identificaram palavras em todos os quadrantes do espaço afetivo sugerindo que estas podem ser classificadas nas dimensões emocionais alerta (desde palavras relaxantes até mais alertadoras) e valência (desde palavras desagradáveis até agradáveis). A confiabilidade média das normas de valência $(\mathrm{r}=0,97)$ e alerta $(\mathrm{r}=0,94)$ foram altas e significativas. Os resultados de alerta ou valência não estiveram associados ao sexo, idade e frequência de ocorrência das palavras em materiais escritos, sugerindo que estes fatores podem ser considerados ortogonais.
\end{abstract}

Palavras-chave: alerta, valência, normas para palavras, SAM

\section{Norms of Arousal and Valence for 908 Portuguese Words}

\begin{abstract}
Norms of arousal and valence for 908 Portuguese words were collected using SAM (Self-Assessment Manikin). In this study 4359 undergraduates from four universities participated. Words from each of the affective space quadrant were identified suggesting that they can be categorized along the arousal (from relaxing to more arousing words) and valence (from unpleasant to pleasant words) emotional dimensions. The reliability of the norms for valence $(r=0,97)$ and arousal $(r=0,94)$ was high and significant. Results showed that arousal and valence were not associated with sex, age or printed word frequency indicating that the factors can be considered orthogonal.
\end{abstract}

Keywords: arousal, valence, word norms, SAM

A pesquisa sobre a emoção se estende para os mais diversos campos do conhecimento humano incluindo a biologia, sociologia, neurociência, etologia, economia e, tradicionalmente, a psicologia. O reconhecimento dos estados emocionais como variável independente tem iluminado questões sobre a relação entre cérebro e comportamento, desenvolvimento da personalidade, relações e interações sociais, cultura, evolução, tomada de decisão, psicopatologia e saúde (Coan \& Allen, 2007).

Estudos experimentais têm evidenciado que estados emocionais ou afetivos podem influenciar os processos cognitivos, e que o fator afetivo deve ser contemplado na compreensão da cognição e memória (Ellis \& Hunt, 1993) apesar de, até o momento, não se ter estabelecida uma integração satisfatória entre cognição e emoção (Newell, Rosenbloom, \& Laird, 1990).

No campo da psicologia, muitos pesquisadores têm examinado a influência das experiências emocionais na cognição humana através de dois fatores ortogonais: o alerta e a valência. Essas dimensões variam do relaxamento à

1 Os autores agradecem a participação de Sthephanie Ferreira de Melo Santos, Karla Patrícia Miranda Rocha e Josely Gomes Guimarães que foram fundamentais para a conclusão deste trabalho.

2 Endereço para correspondência: Universidade de Brasília, Instituto de Psicologia/PPB, Campus Universitário Darcy Ribeiro. Brasília, DF. CEP 70910-900.E-mail: espirito@unb.br excitação e do afeto negativo ao positivo, respectivamente. A valência constitui uma dimensão fundamental da emoção na medida em que possibilita aos indivíduos polarizarem os componentes apetitivos e aversivos, os agradáveis e desagradáveis, os positivos e negativos das experiências humanas. Ela evoca um recorte do conjunto das emoções, enquanto valor hedônico, ao se distanciar da "neutralidade emocional" (Kensinger, 2004).

O alerta é outro conceito importante que tem sido visto como um dos componentes na interpretação dos estímulos. Wundt (1924) já o mencionava como responsável pela tensão e relaxamento, e a psicologia moderna vem utilizando amplamente o conceito de alerta ou atividade e ativação como sinônimos (Russell, Weiss, \& Mendelsohn, 1989), muito embora VaezMousavi, Barry, Rushby e Clarke (2007) façam uma distinção entre alerta e ativação.

Estudos apontam que a interpretação emocional de estímulos verbais ou pictóricos pode modificar o processamento da informação. Diferentes combinações entre níveis de valência e alerta influenciam diferentemente o desempenho da atenção (Jefferies, Smilek, Eich, \& Enns, 2008), memória (Kensinger, 2004; Libkuman, Stabler, \& Otani, 2004; McBride \& Cappeliez, 2004), tomada de decisão (Hackley \& Valle-Inclan, 1999), avaliação de estímulos (Gorn, Pham, \& Sin, 2001), expressão facial (Barrett, 1998), resposta cardiovascular (Neumann \& Waldstein, 2001), processamento de figuras (Lane, Chua, \& Dolan, 1999) e possibilitam aumentar 
ou reverter a assimetria hemisférica (Alfano \& Cimino, 2008) ou, ainda, afetar a supressão da memória (Marx, Marshall, \& Castro, 2008).

No estudo sobre os efeitos destas variáveis emocionais na supressão da informação, Marx et al. (2008) encontraram que estímulos altamente alertadores e prazerosos (alta valência) são mais facilmente lembrados do que estímulos poucos alertadores e igualmente prazerosos. De acordo com os autores esse padrão tem um valor bastante adaptativo, na medida em que evidencia maior alocação de recursos às informações emocionais que nos deixam alertas, conferindo-lhes maior resistência ao esquecimento. $\mathrm{O}$ alerta tem um efeito significativo também sobre a produção de falsas memórias. É mais provável, segundo Corson e Verrier (2007), que ocorram falsas memórias em uma condição de alto alerta, independentemente do tipo de humor (para uma revisão ver Santos \& Stein, 2008).

A emoção pode capturar a atenção dirigindo-a para o processamento de estímulos que evocam respostas emocionais. Pratto e John (1991) mostraram, utilizando uma versão emocional do Efeito Stroop, que era mais difícil ignorar as palavras emocionais (por exemplo, assassinato) do que as neutras (por exemplo, mesa) na nomeação da cor da escrita das palavras.

A busca visual também é influenciada por características emocionais negativas do alvo. Nessa tarefa, o indivíduo deve detectar um alvo no contexto de vários fatores de distração. $\mathrm{O}$ tempo para localizar um rosto com expressão de raiva é menor do que se o rosto for neutro ou alegre (Ohman, Lundqvist, \& Esteves, 2001), ou para localizar cobras e aranhas misturadas a outros estímulos naturais (Ohman, Flykt, \& Esteves, 2001).

As pesquisas de neuroimagem e neurofisiologia ainda não concordaram sobre quais são as regiões envolvidas no processamento das dimensões emocionais do alerta e da valência. Kim, Park, Lee e Sohn (2001) verificaram que a amígdala direita é ativada pela valência e não pelo alerta, o contrário ocorrendo com o córtex pré-frontal, que é ativado por diferentes níveis de alerta. Já Anders, Lotze, Erb, Grodd e Birbaumer (2004) verificaram que as atividades da amígdala e da ínsula estão correlacionadas com a valência emocional negativa. A atividade da região frontomedial e talâmica estão associadas com o alerta e o córtex parietal anterior se relaciona com ambas as dimensões. No entanto, Lewis, Critchley, Rotshtein e Dolan (2007), utilizando palavras afetivas e estímulos quimiosensórios, verificaram que sub-regiões do córtex órbitofrontal processavam a valência, enquanto que a amígdala processava preferencialmente o alerta. Por outro lado, Kensinger e Corkin (2004) identificaram uma resposta aumentada a palavras negativas de alto e baixo alertas no hipocampo, amígdala e lobo parietal inferior.

Em tarefas em que são usadas medidas de potencial evocado relacionado a eventos afetivos, observa-se que o alerta tem uma influência maior que a valência (Rozenkrants, Olofsson, \& Polich, 2008). Mourão-Miranda et al. (2003) encontraram, em um estudo sobre as contribuições independentes e combinadas de alerta e valência, que estímulos alertadores eram suficientes para potencializar o processamento de informações no córtex visual, enquanto que somente a valência não era necessária para deflagrar tal processamento.
A inclusão da emoção na compreensão dos fenômenos psicológicos enfrenta dois desafios metodológicos: como medir e manipular a emoção. De acordo com Smith e Kosslyn (2008), a mensuração da emoção tem sido coletada diretamente através da autoavaliação na qual o sujeito relata diretamente seu humor, ou indiretamente utilizando-se medidas comportamentais ou psicofisiológicas. A manipulação da emoção pode ser produzida induzindo-se estados de humor através, por exemplo, de fotografias, material verbal ou solicitando ao participante que focalize a atenção em memórias carregadas emocionalmente (para uma revisão sobre a eliciação e avaliação da emoção consulte Coan \& Allen, 2007).

No Brasil, o pesquisador em psicologia ainda dispõe de poucas ferramentas para a manipulação da emoção. É possível utilizar as fotografias do IAPS normatizadas em nosso país (Ribeiro, Pompéia, \& Bueno, 2004) e conjuntos de listas de palavras (Santos, Silveira, Gomes, \& Stein, 2009; Stein \& Gomes, 2009). Por sua vez, este trabalho visa oferecer mais um recurso para a pesquisa sobre a emoção com materiais verbais, no caso, palavras isoladas.

O uso de palavras individuais na pesquisa sobre a cognição humana é extensivo e permanente na investigação da memória e outros processos cognitivos como linguagem, raciocínio, aprendizagem de conceitos, reconhecimento de padrões, resolução de problemas e tomada de decisão. Vários são os motivos para esta escolha. Em primeiro lugar, palavras são estímulos com significativo valor ecológico. Estima-se que um indivíduo conheça, em média, o significado de mais de 50.000 palavras associadas a todos os tipos de experiências humanas (Barsalou, 1992). Outra vantagem para o pesquisador é a sua facilidade de manipulação. Palavras têm sido selecionadas de normas que apresentam diferentes características como concretude, frequência de ocorrência em materiais escritos, semanticidade, familiaridade, número de associadas semânticas ou de rima. Esta pesquisa oferece normas sobre duas dimensões emocionais para 908 palavras da língua portuguesa: a valência e o alerta. Estas palavras já foram avaliadas quanto às características concretude (Janczura, Castilho, Oliveira, Van Erven, \& Huang, 2007) e frequência (LAEL, 2006). Assim, o pesquisador poderá controlar ou manipular esses fatores na pesquisa utilizando os respectivos bancos de dados.

\section{Método}

\section{Participantes}

A coleta das normas para alerta incluiu 2.205 participantes, escolhidos por conveniência, cuja participação foi voluntária e anônima. Trinta e um participantes foram excluídos da análise dos resultados porque eram estrangeiros. A amostra apresenta os seguintes atributos: $45 \%$ homens e $55 \%$ mulheres; a idade variou entre 16 e 61 anos $(M=22,32$ anos, $D P=$ 5,91 ) sendo que $80 \%$ da amostra tinha entre 19 e 24 anos; os participantes eram provenientes de 27 unidades da federação do Brasil e a maioria $(58,2 \%)$ nasceu no Distrito Federal (DF); todos os participantes eram estudantes universitários 
distribuídos em quatro Instituições de Ensino Superior do DF, sendo uma pública $(54,8 \%)$ e três particulares $(45,2 \%)$. Os alunos são oriundos de 55 cursos de graduação, sendo $63,9 \%$ matriculados em diferentes cursos, $14,1 \%$ no Direito, $10,5 \%$ na Medicina, 6,4\% na Enfermagem e 5,1\% na Farmácia; o número de semestres cursados na universidade variou entre um e $13(M=3,67, D P=2,42)$ e $85,74 \%$ dos alunos estavam matriculados entre o primeiro e sexto semestres.

$\mathrm{Na}$ coleta da valência participaram 2.154 pessoas. Dezoito estrangeiros foram excluídos da análise. A amostra apresentou as seguintes características: $42,9 \%$ homens e $57,1 \%$ mulheres; a idade variou entre 16 e 61 anos $(M=22,56$ anos, $D P=6,12$ ), sendo que $80 \%$ da amostra possuía entre 18 e 25 anos. Participantes originados de 26 unidades da federação compuseram a amostra, com maior participação de pessoas nascidas no DF $(55,8 \%)$. Todos os respondentes eram estudantes universitários distribuídos em quatro Instituições de Ensino Superior do DF, sendo uma pública $(54,6 \%)$ e três particulares (45,4\%). Cinquenta e um cursos de graduação foram representados, sendo $69,6 \%$ de diferentes cursos, $10,7 \%$ do Direito, $8,4 \%$ da Enfermagem, 6,8\% da Odontologia e $4,5 \%$ da Letras; o número de semestres cursados na universidade variou entre um e $14(M=3,73, D P=2,33)$ e $80 \%$ dos alunos estavam matriculados entre o primeiro e o quinto semestres.

\section{Materiais e Procedimentos}

Foram utilizadas 908 palavras da língua portuguesa selecionadas de Janczura et al. (2007). As palavras foram randomizadas e compuseram listas para a avaliação do alerta em 19 formulários. Após, foram novamente randomizadas e organizadas em outros 19 formulários para a avaliação da valência. Cada formulário continha em média 48 palavras. À direita das palavras foi disposta a escala SAM (Lang, 1980), que é uma escala composta de cinco figuras, que correspondem a bonecos com contornos humanos ou esboços, e quatro espaços em branco, intercaladamente, associados a uma escala que varia de um a nove pontos. Para o julgamento do alerta, os bonecos apresentavam desenhos na região do tórax que variava de um ponto (à esquerda) que parecia aumentar de tamanho em forma de explosão na medida em que sua posição fosse mais extrema (à direita). $\mathrm{O}$ extremo esquerdo desta escala (valor 1) correspondia ao estado máximo de relaxamento e o outro extremo à condição máxima de estimulação (valor 9). Para o julgamento de valência os bonecos apresentavam a boca em posição de tristeza, neutralidade ou sorriso (da esquerda para a direita). O desenho à esquerda da escala correspondia à condição máxima de desagradabilidade (valor 1), e o extremo direito da escala (valor 9), ao máximo de agradabilidade. Em ambas as escalas, o desenho central (valor 5) correspondia a um estado neutro da dimensão emocional considerada. Uma ilustração da escala SAM pode ser vista em Santos et al. (2009).

O papel do respondente era avaliar o quanto as palavras eram relaxantes ou alertadoras ou, ainda, agradáveis ou desagradáveis. Isso era feito assinalando qual dos desenhos correspondia ao julgamento da magnitude da dimensão emocional considerada. A primeira página do instrumento continha campos que deveriam ser preenchidos com dados demográficos (idade, sexo, local de nascimento, curso, semestre ou período e instituição de ensino superior).

A sessão de coleta dos julgamentos da valência ou alerta iniciava com a assinatura do termo de consentimento livre e esclarecido, apresentação das instruções gerais, objetivos e informações sobre a pesquisa, que foram fornecidas pelo pesquisador, em voz alta, seguidas da distribuição dos formulários. Dúvidas sobre a realização da tarefa, principalmente sobre a utilização da escala SAM, foram esclarecidas depois das instruções iniciais. Após, os participantes iniciavam individualmente os respectivos julgamentos. $\mathrm{O}$ tempo para realização da tarefa era livre, mas os participantes levaram 10 minutos, em média, para realizar os julgamentos. Os participantes foram testados, nas salas de aula das IES, em grupos que variavam de 30 a 100 indivíduos. Cada participante julgou apenas uma das dimensões emocionais de cada palavra. A pesquisa foi aprovada pelo Comitê de Ética em Pesquisa SES/DF protocolo no 034/2007.

\section{Resultados}

O alerta de cada palavra foi avaliado por, pelo menos, 102 participantes $(M=114,42, D P=7,28)$; e, a valência por, no mínimo, 104 participantes $(M=112,42, D P=7,21)$. Foram excluídos os julgamentos em branco ou mais de um julgamento para a mesma palavra.

Avaliou-se a confiabilidade das normas de valência e alerta dividindo-se, aleatoriamente, os participantes em dois subgrupos (método das metades) e calculando-se correlações de Pearson. A correlação para a valência foi 0,97 , e a correlação para o alerta foi 0,94 . Todas as correlações foram significativas ao nível de 0,01 (bilateral). Utilizando procedimento semelhante, foram calculadas ANOVAS, uma para cada dimensão, no qual o grupo de respondentes foi, aleatoriamente, dividido em dois subgrupos e a diferença entre as médias dos julgamentos foi comparada. Nenhuma das ANOVAS foi significativa ao nível de significância de 0,05 , o que mostra não haver diferenças entre os julgamentos.

$\mathrm{O}$ anexo apresenta as médias e os desvios padrão dos julgamentos de alerta e valência para cada palavra. A distribuição dos julgamentos de valência teve uma amplitude de 7,23 (intervalo $=1,35$ a 8,58), assimetria $=-0,327$, curtose $=-0,995$, e uma forma levemente bimodal, o que revela que as palavras foram bem distribuídas entre positivas, neutras e negativas. A maior concentração de palavras ocorreu no intervalo 4,68 e 7,99. O alerta exibiu uma distribuição unimodal (amplitude $=6,81$, intervalo $=1,75-8,56$; assimetria $=0,329 ;$ curtose $=-0,788)$, sendo que à maioria das palavras foi assinalado um valor médio entre 2,65 e 5,48, mostrando, portanto, um nível mais alto de alerta para a maioria das palavras.

O cruzamento da distribuição entre os julgamentos de alerta e valência pode ser observada no "espaço afetivo" (Bradley \& Lang, 2007), delineando-se o espaço bi-dimensional definido pelas médias dos julgamentos em cada dimensão. Há uma relação evidente entre as dimensões: níveis superiores 


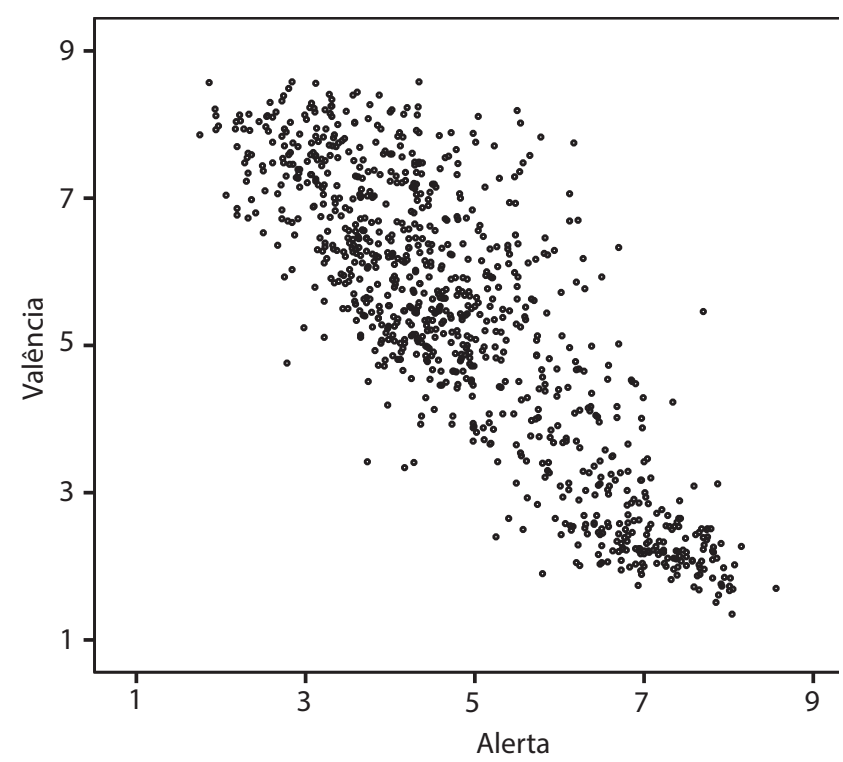

Figura 1. Distribuição de frequência entre valência e alerta.

de valência da palavra estão associados a níveis inferiores de alerta e vice-versa. Essa relação é observada na Figura 1.

O espaço afetivo revela que a maioria das palavras avaliadas se concentra em dois quadrantes onde os estímulos são percebidos como mais agradáveis e relaxantes, ou mais desagradáveis, porém com níveis altos de alerta. Nenhuma palavra foi percebida emocionalmente como extremamente desagradável e relaxante ou, extremamente alertadora e agradável. A Figura 2 apresenta alguns exemplos de palavras nos quatro quadrantes do espaço afetivo.

O padrão do espaço afetivo observado com palavras julgadas isoladamente, notadamente de uma correlação negativa entre as variáveis, é diferente de padrões encontrados para palavras agrupadas em listas (e.g., Santos et al., 2009), ou estímulos pictóricos (e.g., Bradley \& Lang, 2007) nos quais a distribuição tem uma forma aproximada de bumerangue. Isto é, se a valência é associada ao eixo da abscissa e o alerta ao eixo da ordenada, então se verifica uma curva em forma de $\mathrm{U}$.

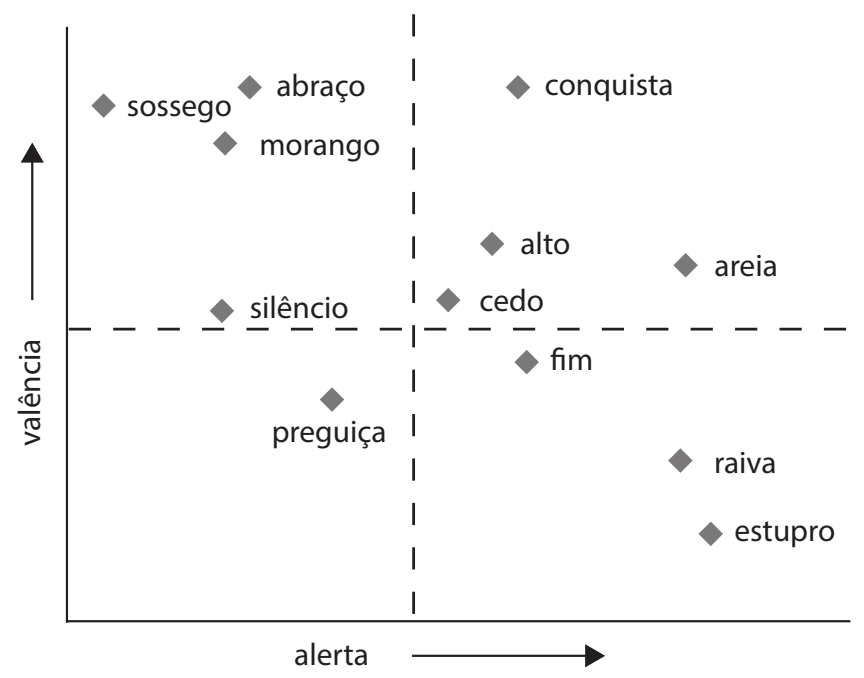

Figura 2. Exemplos de palavras em função do quadrante afetivo.
Foi verificado se a frequência das palavras (LAEL, 2006) e a concretude (Janczura et al., 2007) estavam correlacionadas com os julgamentos de alerta e valência. Correlações de Pearson entre as frequências das palavras e a média do alerta $(r=0,03, p=0,31)$ e entre a média da concretude e a média do alerta $(r=0,02, p=0,62)$ mostraram que os fatores são ortogonais, assim como entre a frequência e a média da valência $(r=-0,03, p=0,34)$, e entre a média da concretude e da valência $(r=-0,01, p=0,71)$.

Por fim, foram avaliados se a idade e o sexo do respondente estiveram associados aos julgamentos de alerta e valência das palavras. Para a idade, foram calculadas correlações de Pearson, para os 19 formulários de alerta e igual número de formulários de valência. De modo a evitar correlações espúrias provenientes de outliers, foram excluídos da análise os participantes maiores de 35 anos. Nenhuma correlação atingiu o nível de significância de 0,05 . Para o sexo foram feitas 38 ANOVAS (19 para alerta e 19 para valência), não sendo encontradas semelhanças entre as médias ao nível de significância de 0,05 .

\section{Conclusões}

Os resultados relatados sugerem que o julgamento da carga emocional das palavras obedece a um padrão bastante delineado. Ou seja, na medida em que uma palavra é percebida como emocionalmente negativa também mais alerta o indivíduo dirige à mesma. Por outro lado, um estado de maior relaxamento está associado à percepção de palavras emocionalmente positivas. Esses resultados são relevantes na medida em que apontam para a necessidade do controle desses atributos das palavras em tarefas experimentais, principalmente no âmbito dos estudos em cognição e sua interação com a emoção.

$O$ fato de fatores como a idade e o sexo não estarem associados aos julgamentos evidencia que as dimensões alerta e valência são atributos independentes das palavras assim como a concretude e a frequência. Essa possibilidade permite que os respectivos fatores sejam manipulados ou controlados independentemente em pesquisas que utilizem esse material verbal.

Embora este estudo venha acrescentar informações ao banco de dados para esse tipo de material, considerando-se as normas já coletadas de associação semânticas para conceitos naturais (Janczura, 1996), as normas de tríades para testes de memória (Pompéia, Paes, \& Bueno, 2003), as normas de palavras associadas DRM (Stein, Feix, \& Rohenkohl, 2006; Stein \& Gomes, 2009), as normas de frequência (LAEL, 2006; Pinheiro, 1996; Sardinha, 2004), as normas de figuras de objetos comuns (Pompéia, Miranda, \& Bueno, 2001), e as normas de associação semântica para palavras contextualizadas (Janczura, 2005), há a necessidade de se identificar outros atributos de materiais verbais que, notadamente, influenciam o desempenho cognitivo dos indivíduos como, por exemplo, a rede de palavras associadas aos alvos usados na pesquisa e suas respectivas características (Nelson, McKinney, Gee, \& Janczura, 1998; McEvoy, Nelson, \& Komatsu, 1999). 


\section{Referências}

Alfano, K. M., \& Cimino, C. R. (2008). Alteration of expected hemispheric asymmetries: Valence and arousal effects in neuropsychological models of emotion. Brain and Cognition, 66, 213-220.

Anders, S., Lotze, M., Erb, M., Grodd, W., \& Birbaumer, N. (2004). Brain activity underlying emotional valence and arousal: A response-related fMRI study. Human Brain Mapping, 23, 200-209.

Barrett, L. F. (1998). Discrete emotions or dimensions? The role of valence focus and arousal focus. Cognition \& Emotion, 12, 579-599.

Barsalou, L. W. (1992). Cognitive psychology: An overview for cognitive scientists. Hillsdale: Lawrence Erlbaum Associates Publishers.

Bradley, M. M., \& Lang, P. J. (2007). The International Affective Picture System (IAPS) in the study of emotion and attention. In J. A. Coan, \& J. J. B. Allen (Eds), Handbook of emotion elicitation and assessment (pp. 29-46). Oxford: University Press.

Coan, J. A., \& Allen, J. J. B. (2007). Handbook of emotion elicitation and assessment. Oxford: University Press.

Corson, Y., \& Verrier, N. (2007). Emotions and false memories: Valence or arousal? Psychological Science, 18, 208-211.

Ellis, H. C., \& Hunt, R. R. (1993). Fundamentals of Cognitive Psychology. Madison: Brown \& Benchmark.

Gorn, G., Pham, M. T., \& Sin, L. Y. (2001). When arousal influences ad evaluation and valence does not (and vice versa). Journal of Consumer Psychology, 11, 43-55.

Hackley, S. A., \& Valle-Inclan, F. (1999). Accessory stimulus effects on selection: Does arousal speed decision making? Journal of Cognitive Neuroscience, 11, 321-329.

Janczura, G. A. (1996). Normas associativas para 69 categorias semânticas. Psicologia: Teoria e Pesquisa, 12, 237-244.

Janczura, G. A. (2005). Contexto e normas de associação semântica: A redução do campo semântico. Paidéia, 15, 417-425.

Janczura, G. A., Castilho, G.M., Oliveira, N. R., van Erven, T. J. C., \& Huang, T. P. (2007). Normas de concretude para 909 palavras da língua portuguesa. Psicologia, Teoria e Pesquisa, 23, 195-204.

Jefferies, L. N., Smilek, D., Eich, E., \& Enns, J. T. (2008). Emotional valence and arousal interact in the control of attention. Psychological Science, 19, 290-295.

Kensinger, E. A. (2004). Remembering emotional experiences: The contribution of valence and arousal. Reviews in the Neurosciences, 15, 241-251.

Kensinger, E. A., \& Corkin, S. (2004). Two routes to emotional memory: Distinct neural processes for valence and arousal. PNAS, 101, 3310-3315.

Kim, Y., Park, S., Lee, K., \& Sohn, J. (2001). Activation of the amygdale by valence dimension, not by arousal dimension of emotion: A fMRI study. NeuroImage, 13, Part 2 of 2 Parts.

LAEL (2006). Banco de Português, sub-corpora escrito. Retrieved from http://ww2.lael.pucsp.br/corpora/bp/index.htm, acesso em 07/04/06.

Lane, R. D., Chua, P. M. -L., \& Dolan, R. J. (1999). Common effects of emotional valence, arousal and attention on neural activation during visual processing of pictures. Neuropsychologia, 37, 989-997.
Lang, P. J. (1980). Behavioral treatment and bio-behavioral assessment? Computer applications. In J. B. Sidowski, J. H. Johnson, \& T. A. Williams (Eds.), Technology in mental health care delivery system (pp. 119-137). Norwood: Ablex.

Lewis, P. A., Critchley, H. D., Rotshtein, P., \& Dolan, R. J. (2007). Neural correlates of processing valence and arousal in affective words. Cerebral Cortex, 17, 742-748.

Libkuman, T. M., Stabler, C. L., \& Otani, H. (2004). Arousal, valence, and memory for detail. Memory, 12, 237-247.

Marx, B. P., Marshall, P. J., \& Castro, F. (2008). The moderating effects of stimulus valence and arousal on memory suppression. Emotion, 8, 199-207.

McBride, C., \& Cappeliez, P. (2004). Effects of manipulating valence and arousal components of mood on specificity of autobiographical memory. Psychological Reports, 95, 615-630.

McEvoy, C. L., Nelson, D. L., \& Komatsu, T. (1999). What is the connection between true and false memories? The differential roles of inter item associations in recall and recognition. Journal of Experimental Psychology: Learning, Memory, and Cognition, 25, 1177-1194.

Mourão-Miranda, J., Volchan, E., Moll, J., de Oliveira-Souza, R., Oliveira, L., Bramati, I., \& Pessoa, L. (2003). Contributions of stimulus valence and arousal to visual system activation during emotional perception fMRI. NeuroImage, 20, 1955-1963.

Nelson, D. L., McKinney, V. M., Gee, N. R., \& Janczura, G. A. (1998). Interpreting the influence of implicitly activated memories on recall and recognition. Psychological Review, 105, 299-324.

Neumann, S. A., \& Waldstein, S. R. (2001). Similar patterns of cardiovascular response during emotional activation as a function of affective valence and arousal and gender. Journal of Psychosomatic Research, 50, 245-253.

Newell A., Rosenbloom, P. S., \& Laird, J. E. (1990). Symbolic architectures for cognition. In M. I. Posner (Ed.), Foundations of Cognitive Science (pp. 93-131). Cambridge, MA: MIT Press.

Ohman, A., Flykt, A., \& Esteves, F. (2001). Emotion drives attention: Detecting the snake in the Grass. Journal of Experimental Psychology: General, 130, 466-478.

Ohman, A., Lundqvist, D., \& Esteves, F. (2001). The face in the crowd revisited: A threat advantage with schematic stimuli. Journal of Personality and Social Psychology, 80, 381-396.

Pinheiro, A. M. V. (1996). Contagem de frequência de ocorrência de palavras expostas a crianças na faixa pré-escolar e séries iniciais do primeiro grau. Associação Brasileira de Dislexia, São Paulo.

Pompéia, S., Miranda, M. C., \& Bueno, O. F. A. (2001). A set of 400 pictures standardized for Portuguese: Norms for name agreement, familiarity and visual complexity for children and adults. Arquivos de Neuro-Psiquiatria, 59(2B), 330-337.

Pompéia, S., Paes, A. T., \& Bueno, O. F. A. (2003). Teste de complementação de letras: Estímulos para uso no Brasil. Psicologia: Teoria e Pesquisa, 19, 65-73.

Pratto, F., \& John, O. P. (1991). Automatic vigilance: The attention grabbing power of negative social information. Journal of Personality and Social Psychology, 61, 380-391.

Ribeiro, R. L. , Pompéia, S., \& Bueno, O. F. A. (2004). Normas brasileiras para o International Affective Picture System (IAPS): Comunicação breve. Revista de Psiquiatria, 26, 190-194. 
Rozenkrants, B., Olofsson, J., \& Polich, J. (2008). Affective visual event-related potentials: Arousal, valence, and repetition effects for normal and distorted pictures. International Journal of Psychophysiology, 67, 114-123.

Russell, J. A., Weiss, A., \& Mendelsohn, G. A. (1989). Affect grid: A single-item scale of pleasure and arousal. Journal of Personality and Social Psychology, 57, 493-502.

Santos, R. F., \& Stein, L. M. (2008). A influência da emoção nas falsas memórias: Uma revisão crítica. Psicologia USP, 19, 415-434.

Santos, R. F., Silveira, R. A. T., Gomes, C. F. A., \& Stein, L. M. (2009). Normas de emocionalidade para a versão brasileira do paradigma Deese-Roediger-McDermott (DRM). Psicologia: Teoria e Pesquisa, 25, 387-394.

Sardinha, T. B. (2004). Linguística de Corpus. Barueri, SP: Manole. Smith, E. E., \& Kosslyn, S. M. (2008). Cognitive psychology: Mind and brain. New Delhi: Prentice-Hall of India.

Stein, L. M., Feix, L. F., \& Rohenkohl, G. (2006). Avanços metodológicos no estudo das falsas memórias: Construção e normatização do procedimento da lista de palavras associadas à realidade brasileira. Psicologia: Reflexão e Crítica, 19, 166-176.
Stein, L. M., \& Gomes, C. F. A. (2009). Normas brasileiras para listas de palavras associadas: Associação semântica, concretude, frequência e emocionalidade. Psicologia: Teoria e Pesquisa, 25, 537-546.

VaezMousavi, S. M., Barry, R. J., Rushby, J., \& Clarke, A. (2007). Evidence for differentiation of arousal and activation in normal adults. Acta Neurobiologiae Experimentalis, 67, 179-186.

Wundt, W. (1924). An Introduction to psychology. Edinburgo: Ballantyne Press.
Recebido em 22.07.2011

Primeira decisão editorial em 16.07.2012

Versão final em 23.08.2012

Aceito em 29.10.2012 


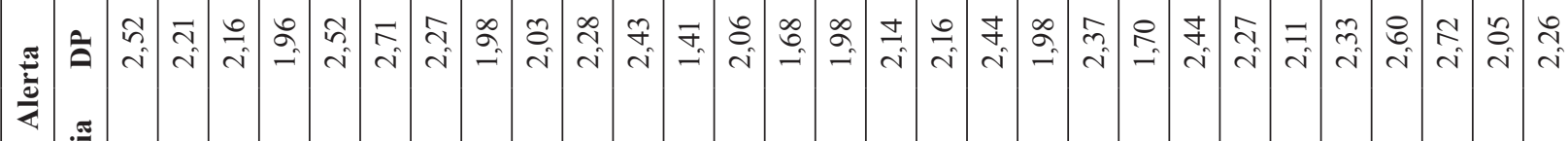

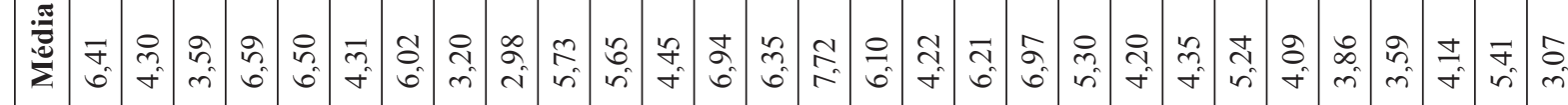

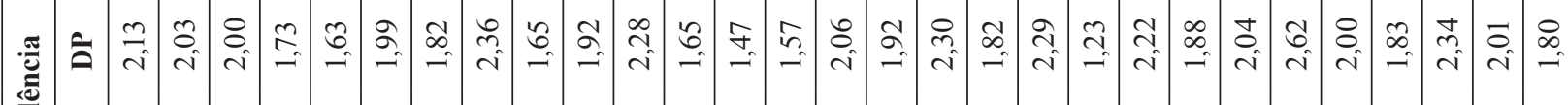

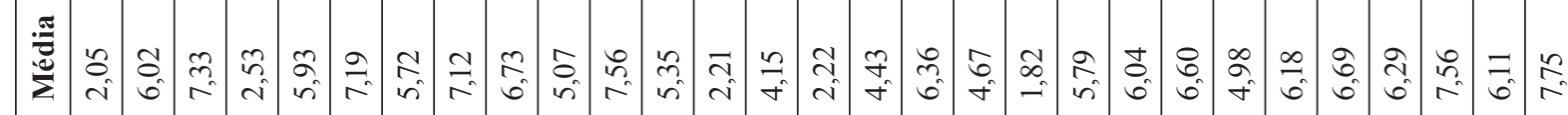

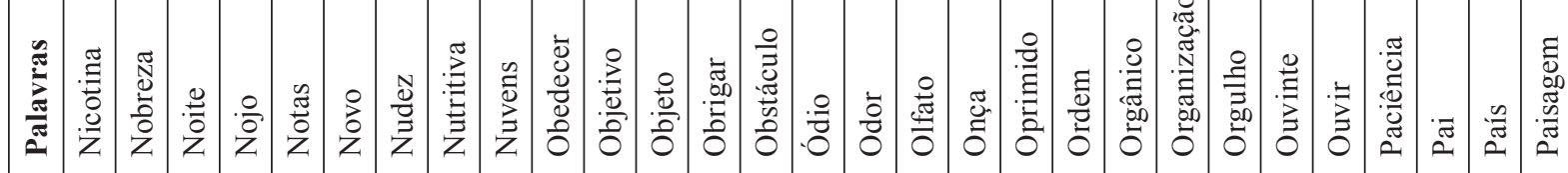

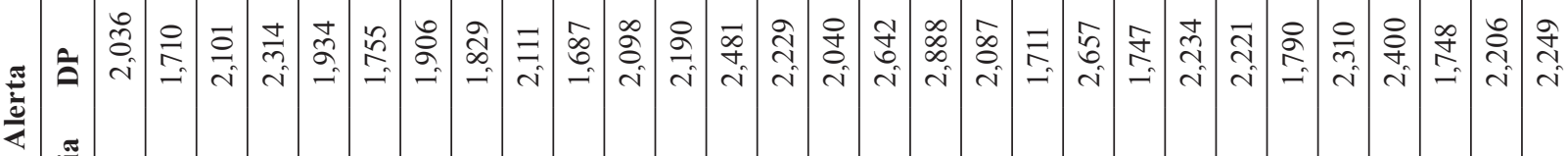

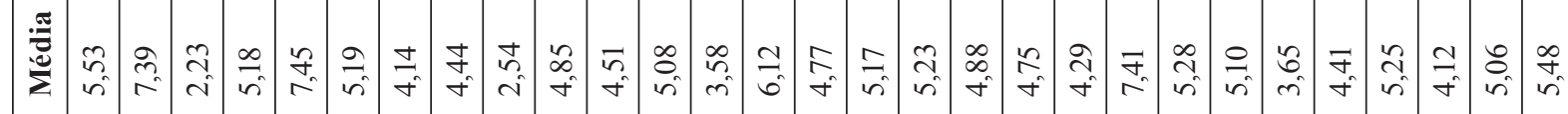

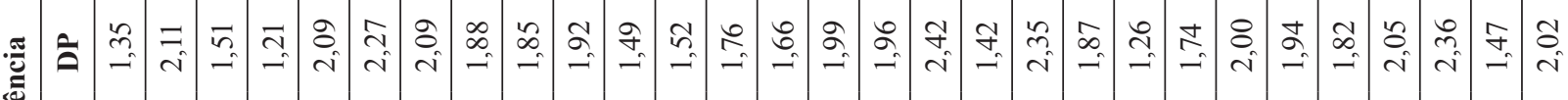

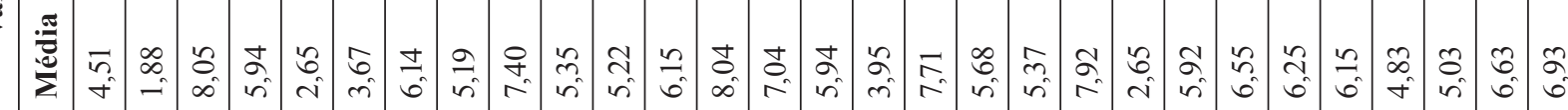

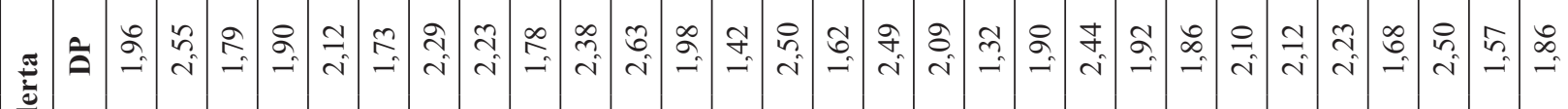

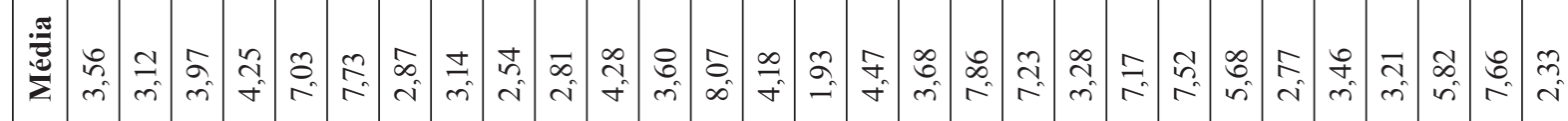

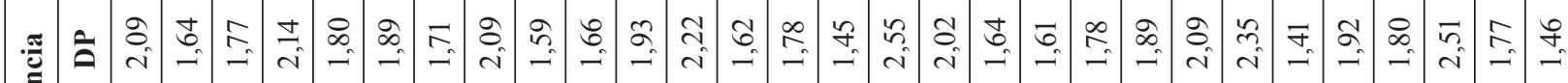
$\stackrel{\frac{\pi}{\pi}}{>}$

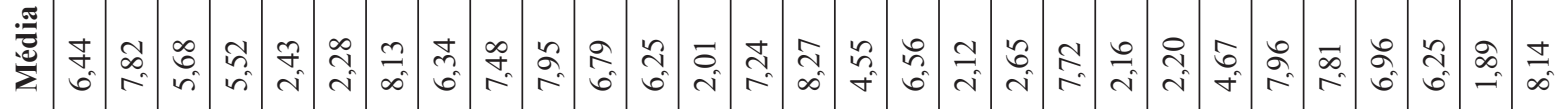




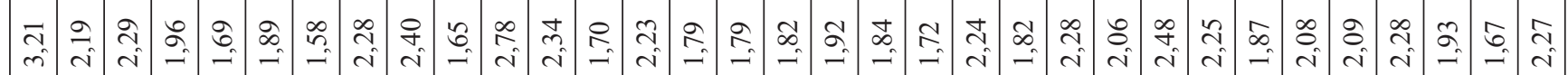

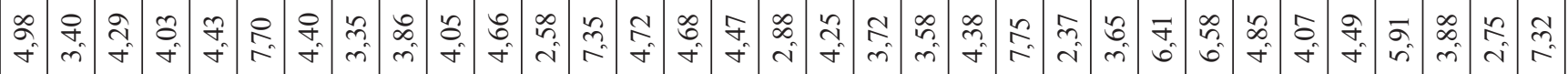

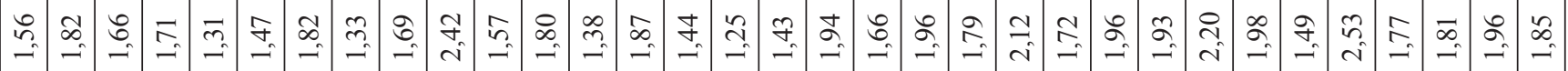

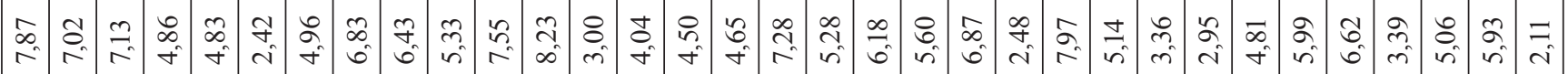

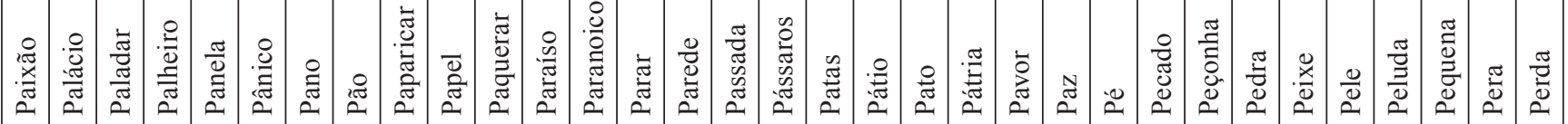

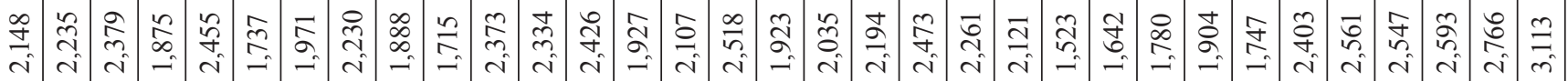

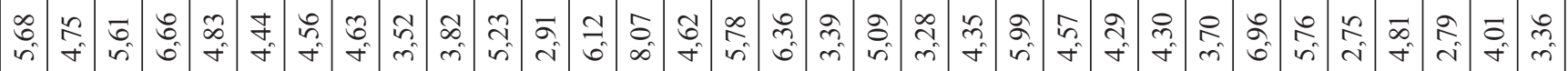

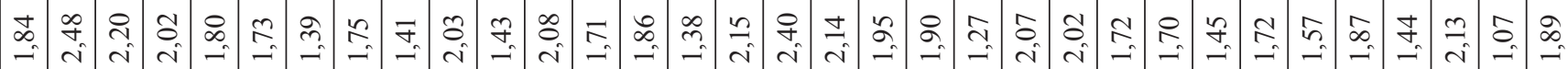

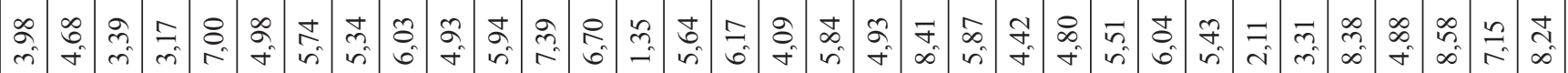

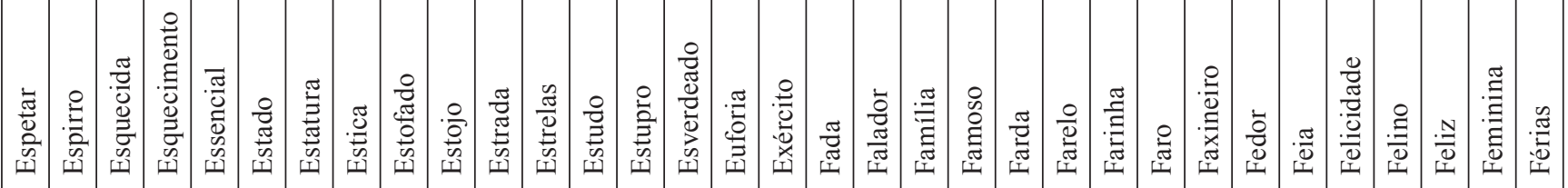

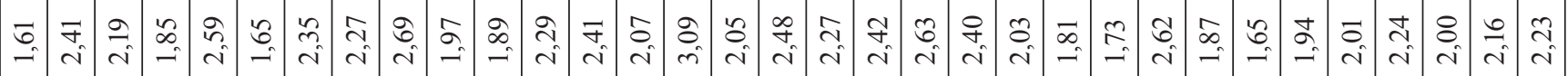

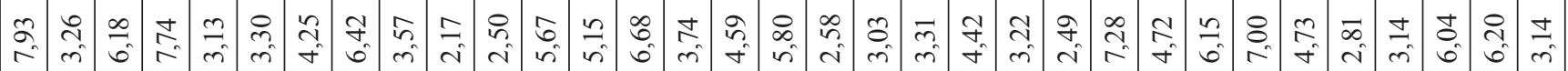

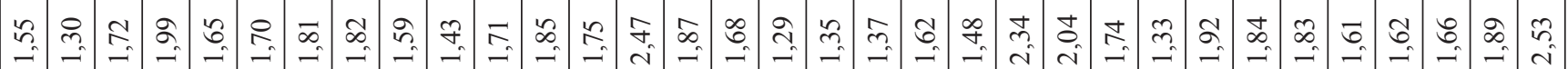

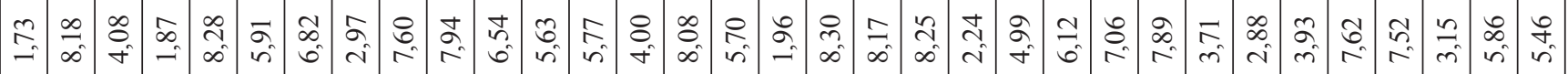

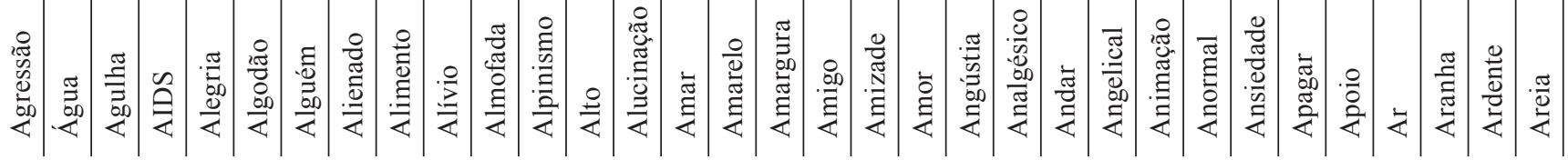




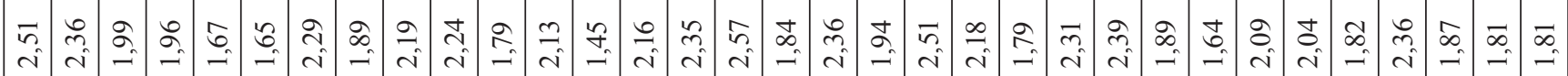

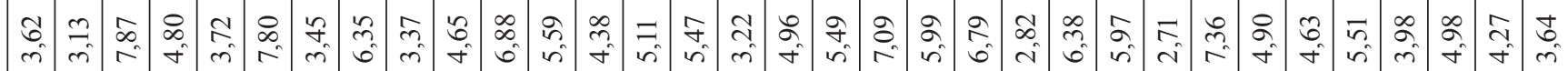

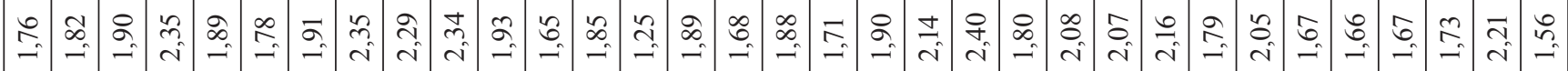

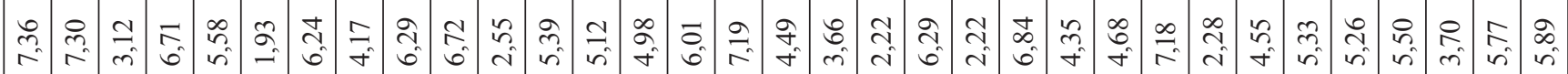

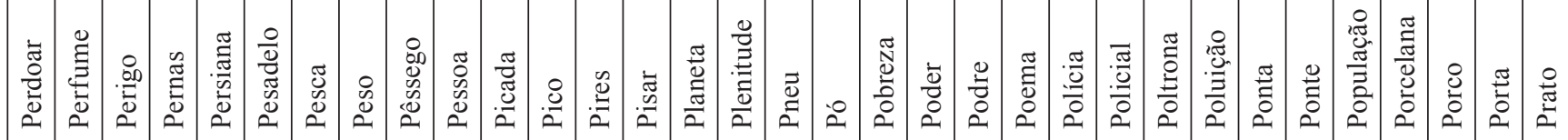

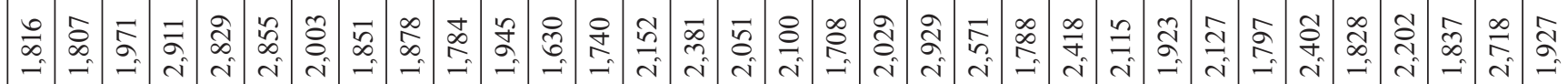

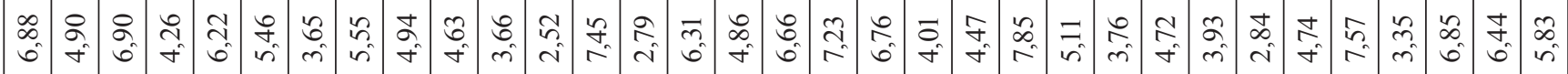

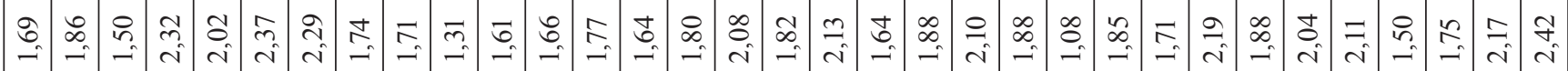

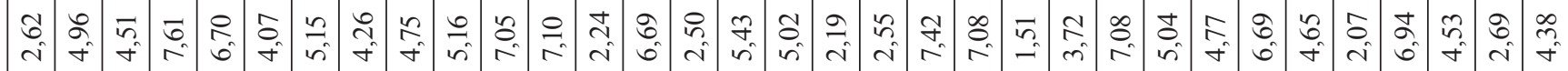

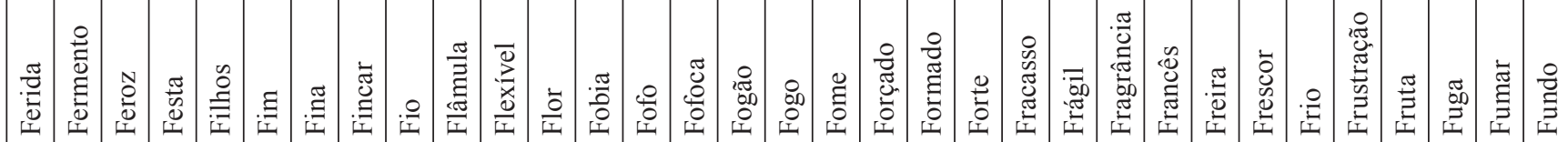

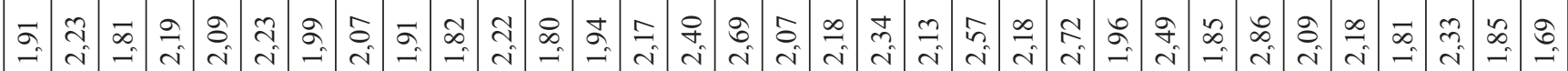

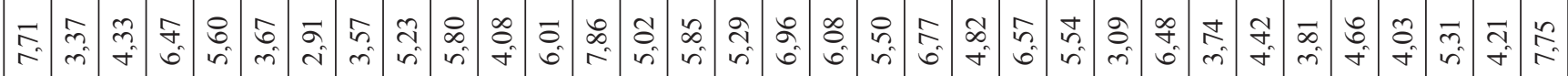

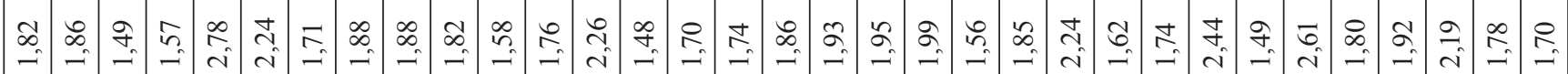

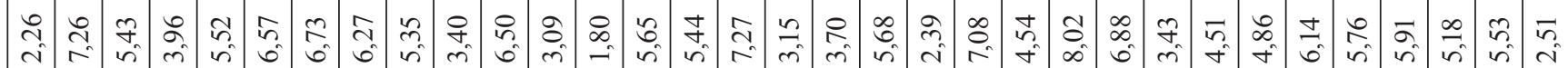

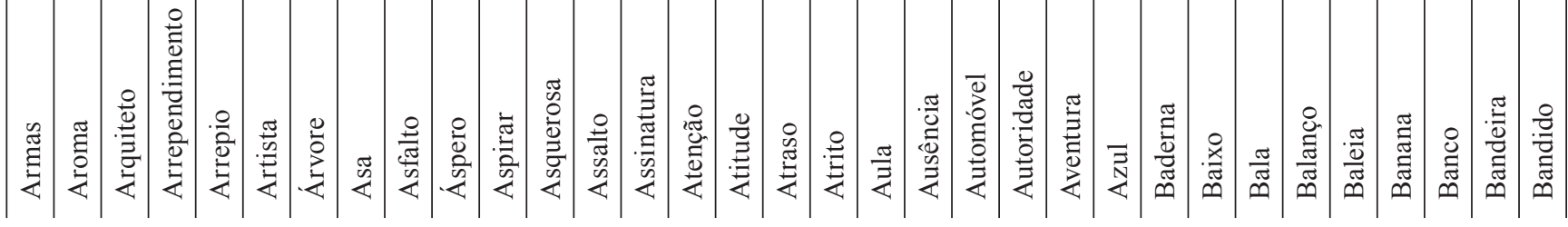




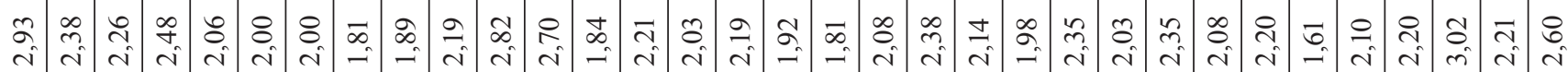

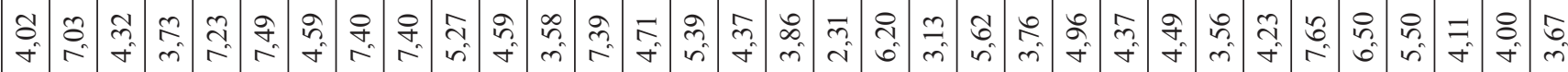

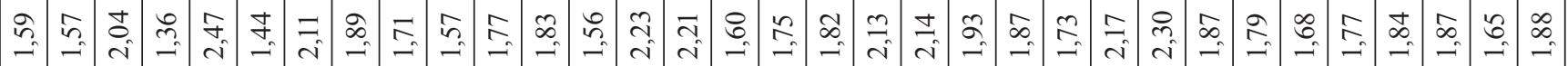

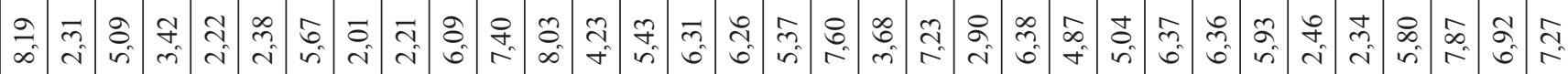

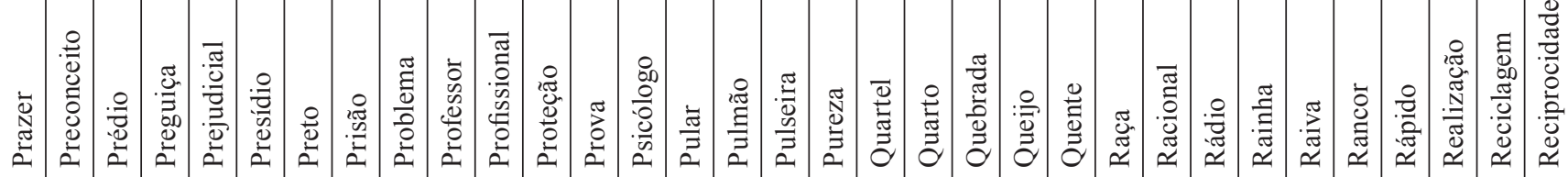

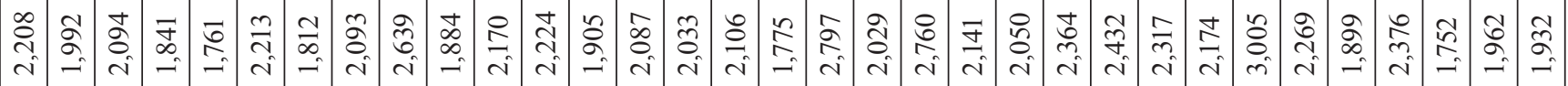

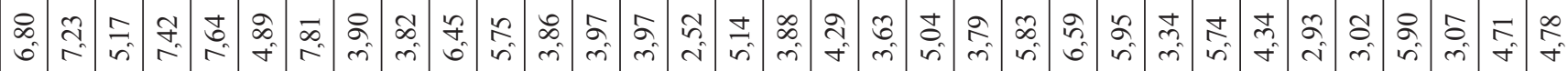

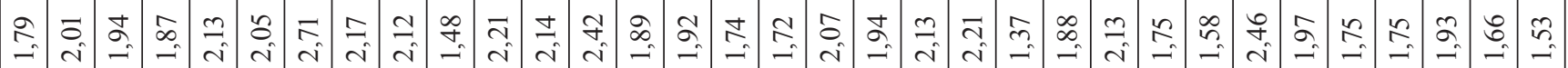

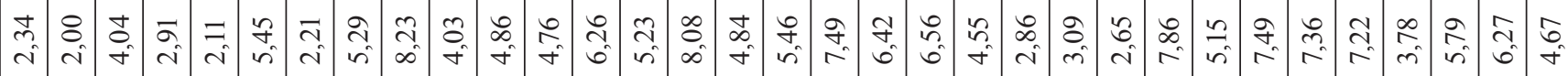

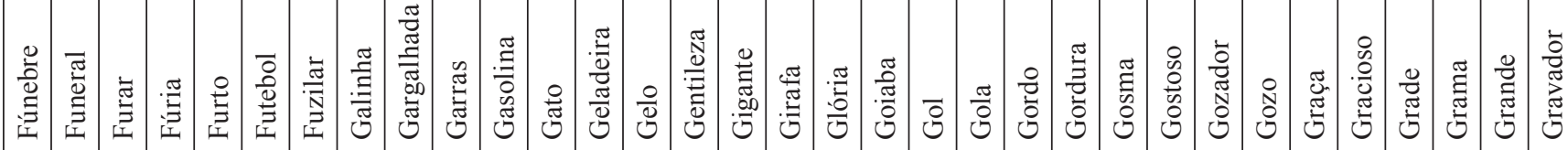

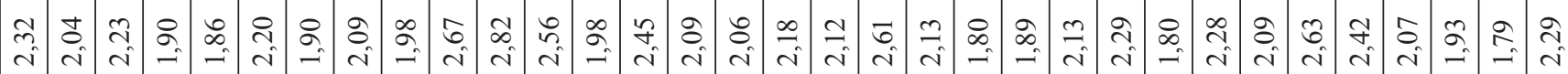

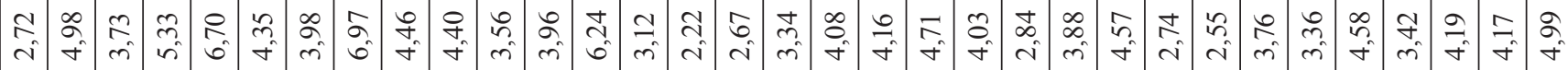

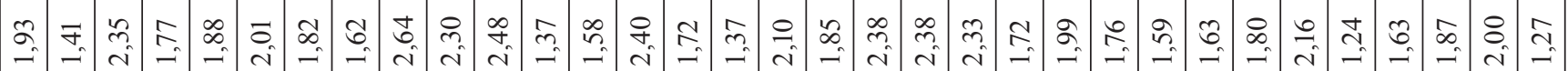

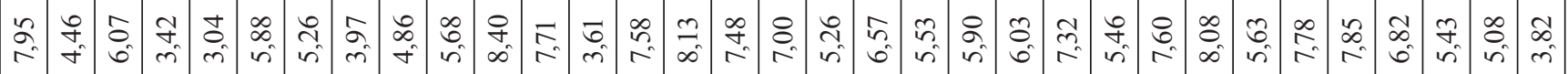

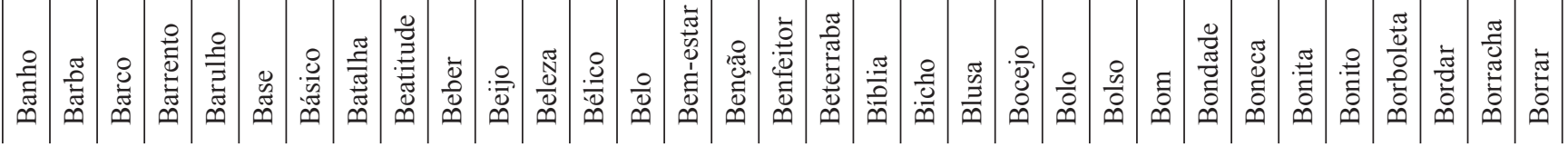




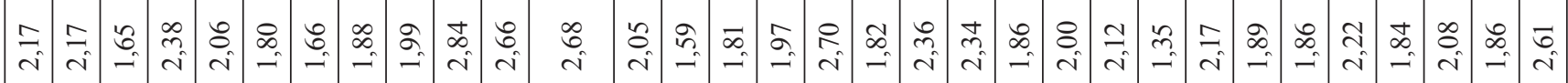

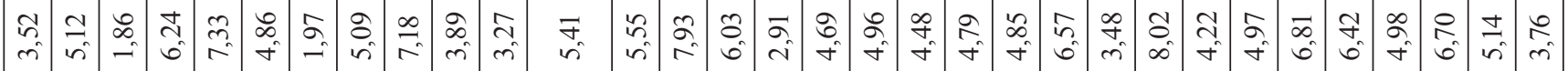

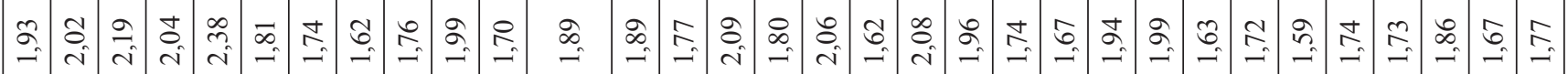

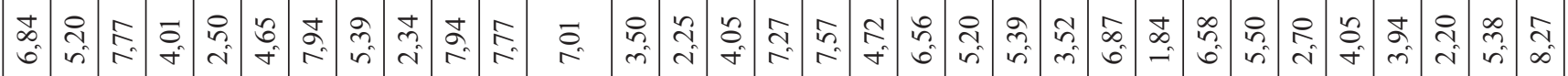

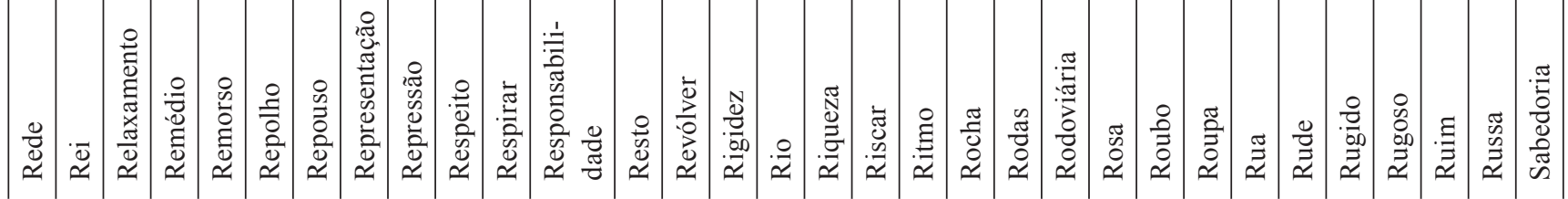

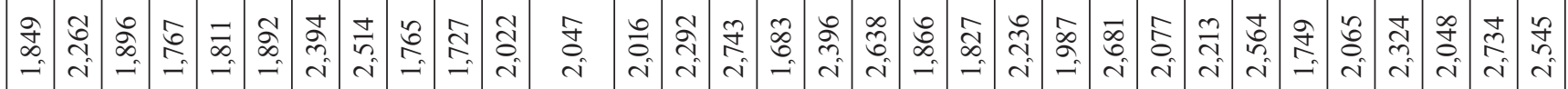

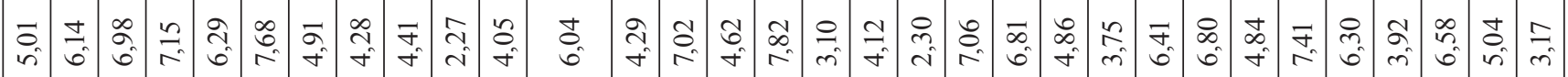

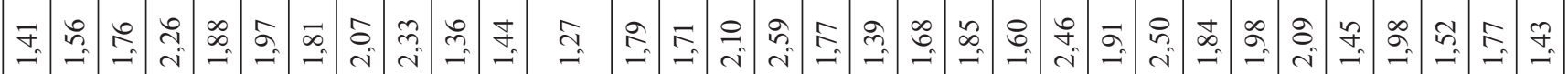

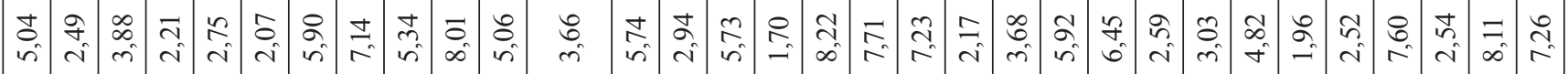

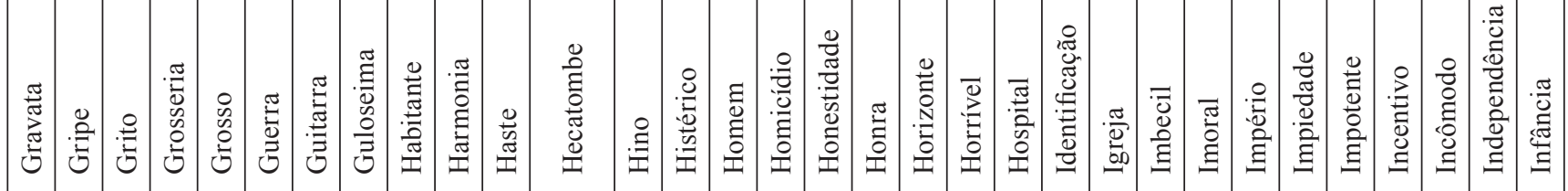

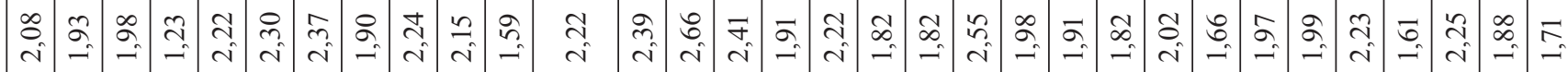

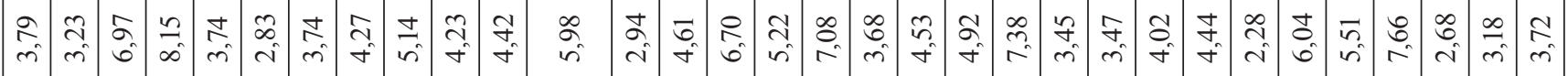

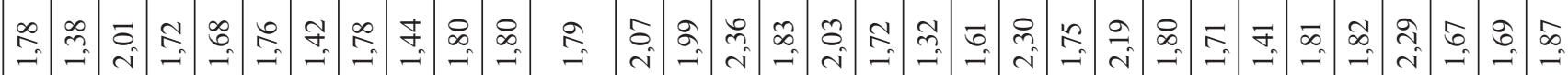

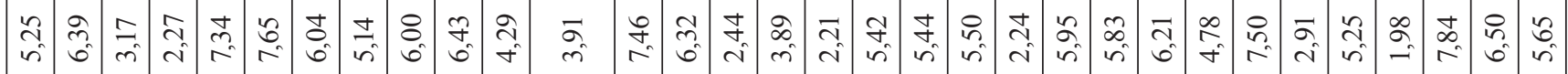

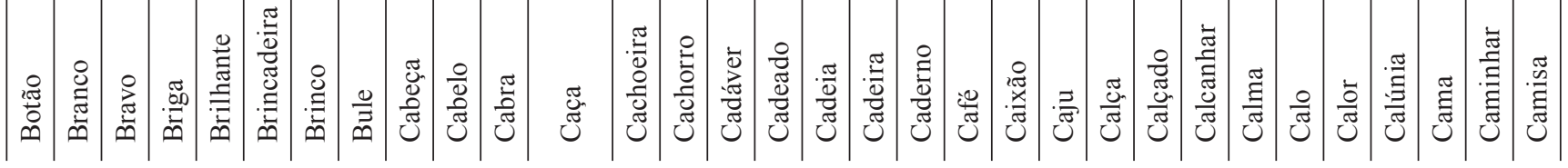




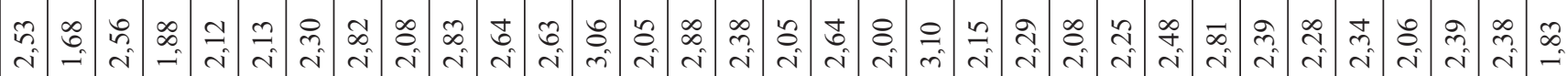

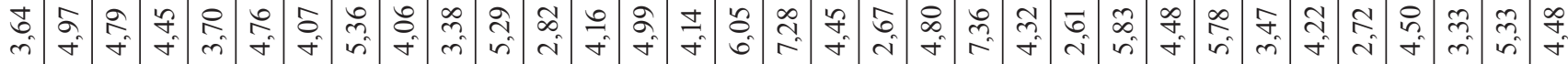

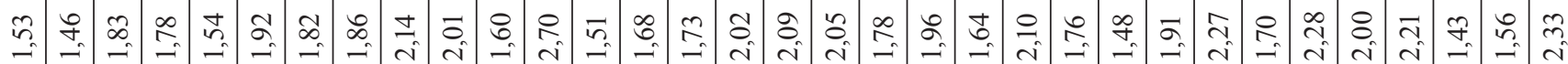

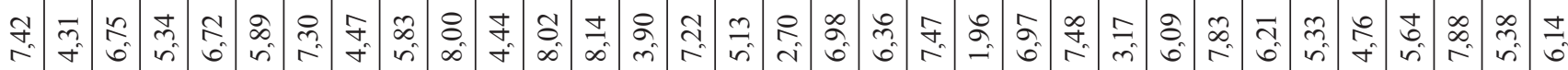

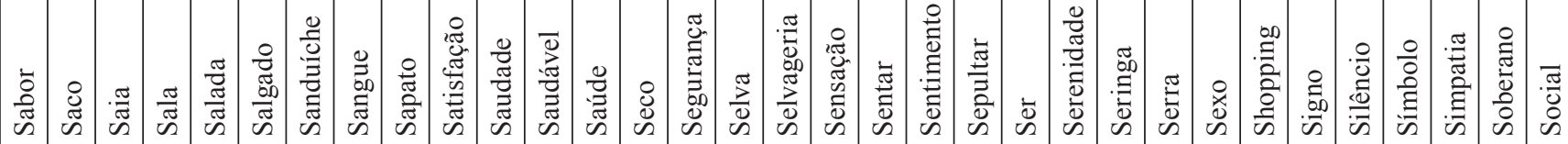

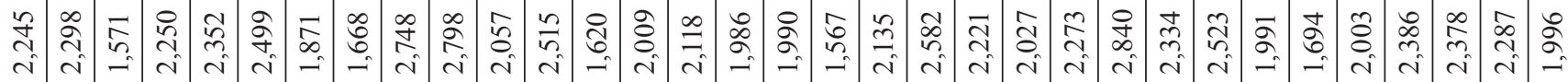

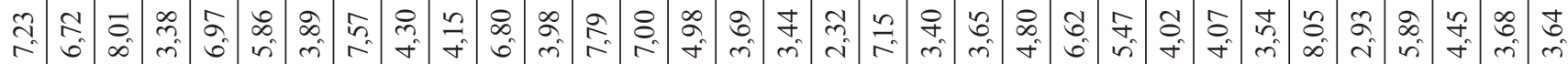

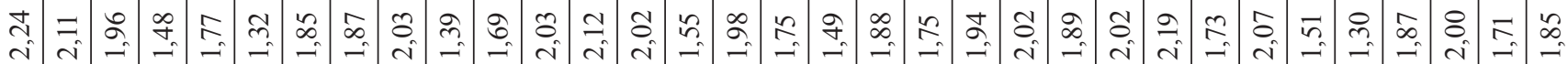

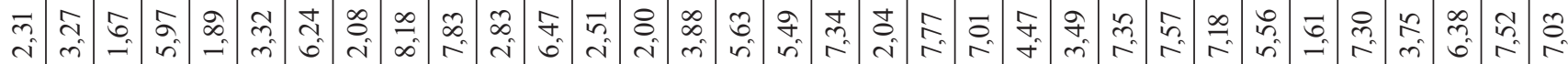

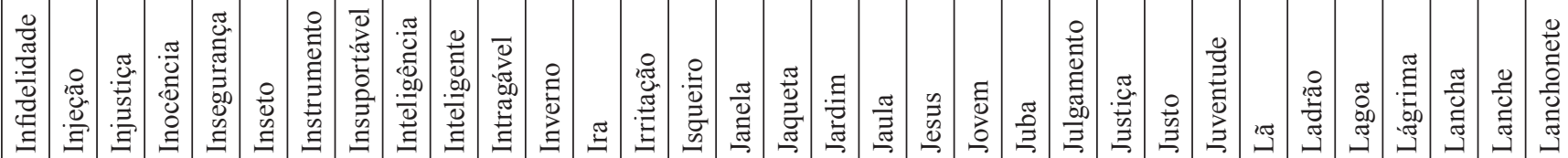

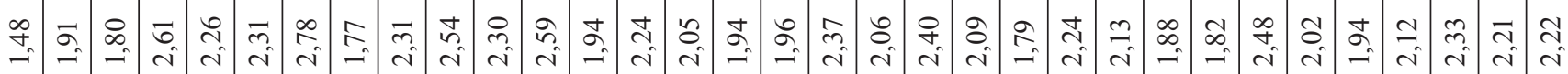

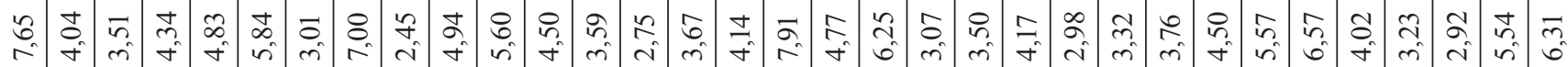

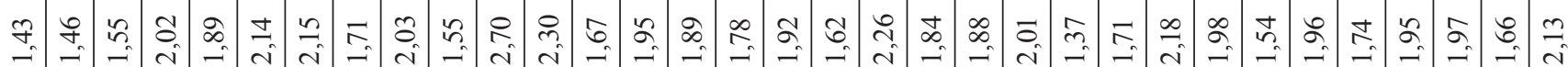

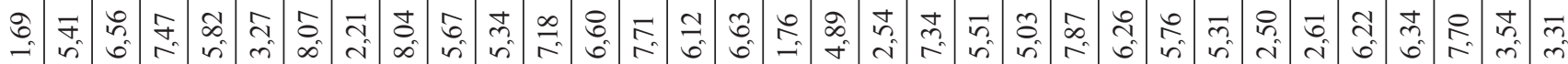

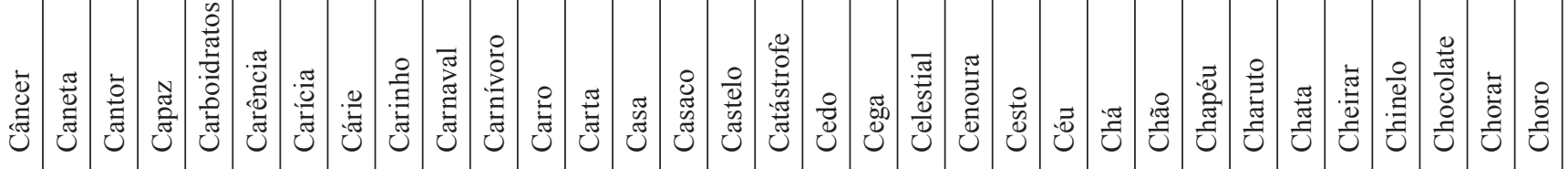




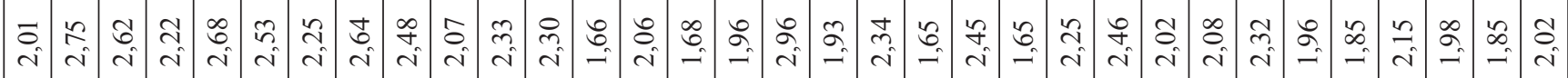

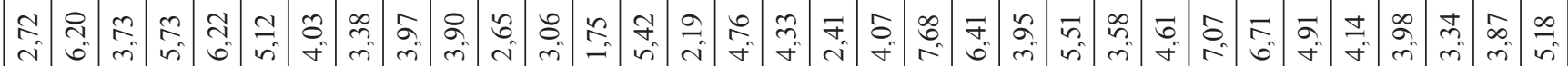

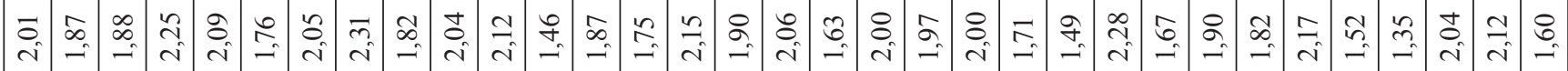

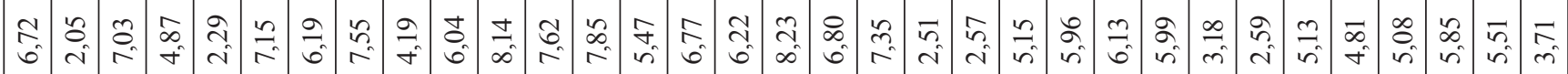

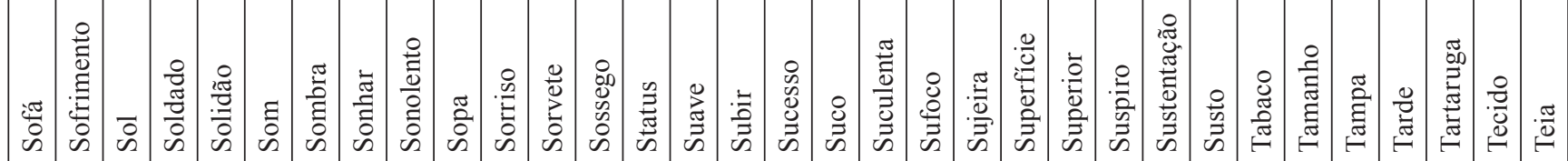

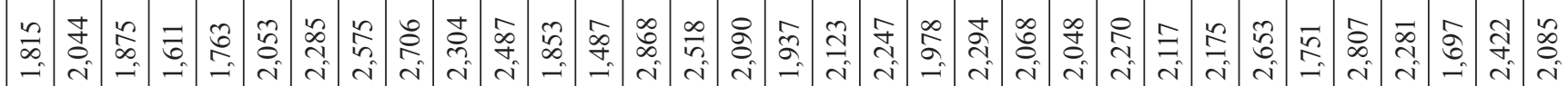

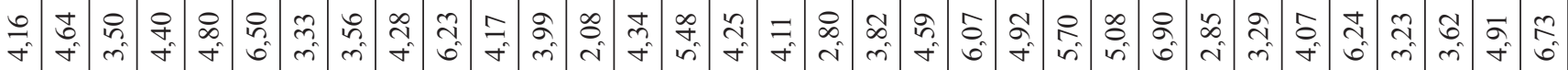

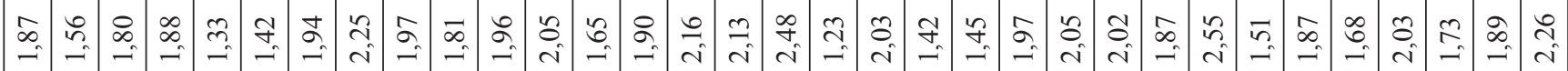

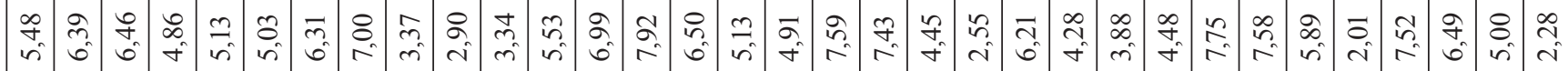

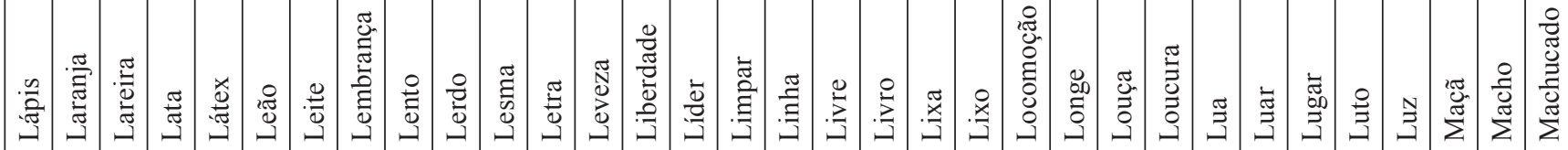

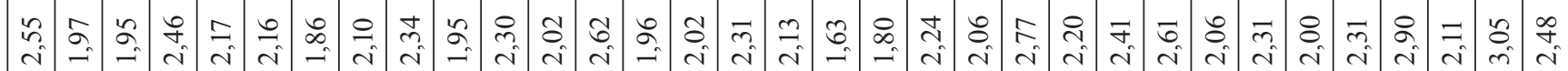

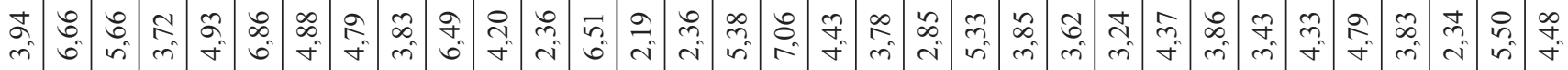

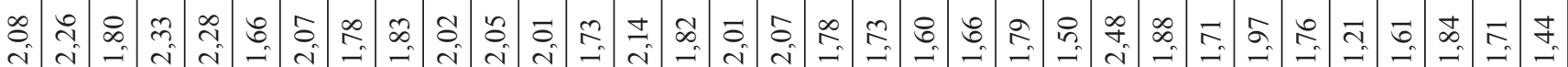

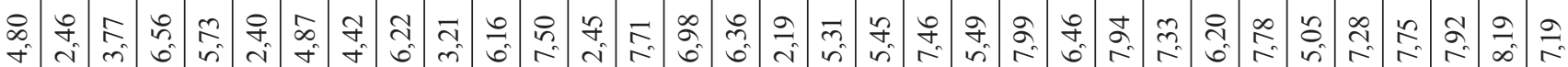

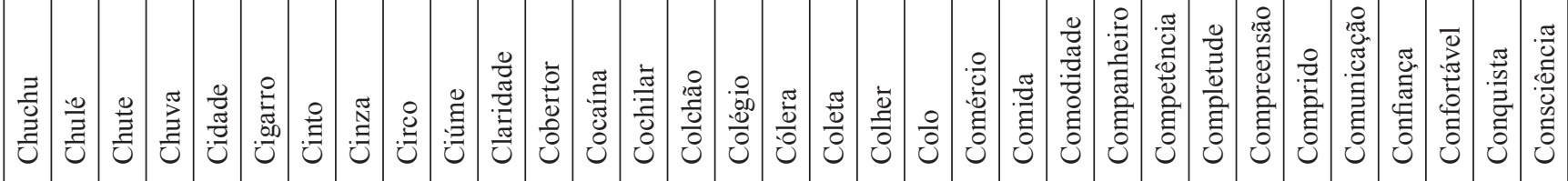




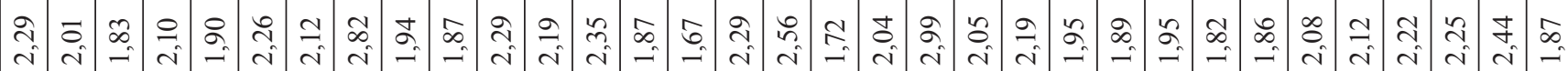

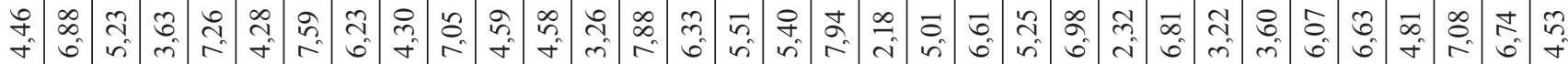

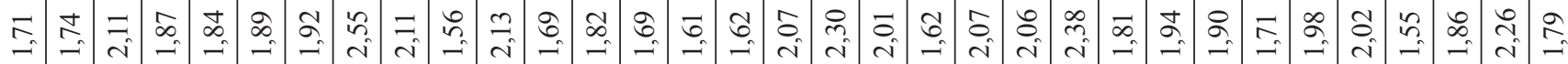

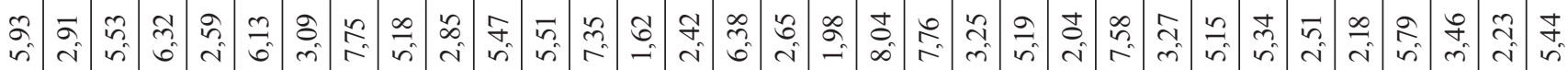
(

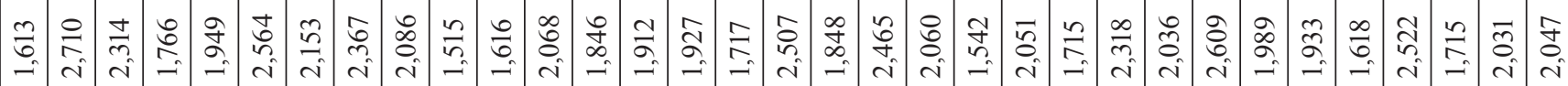

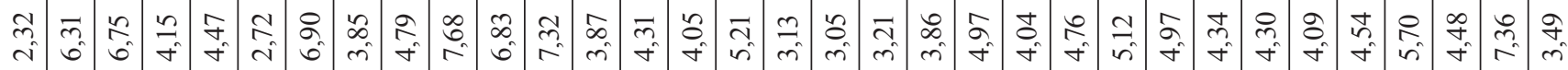

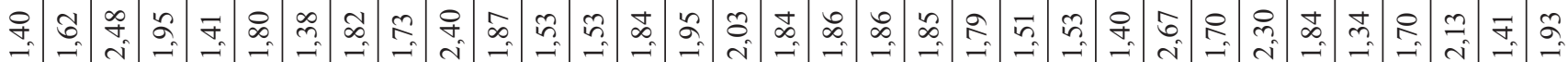

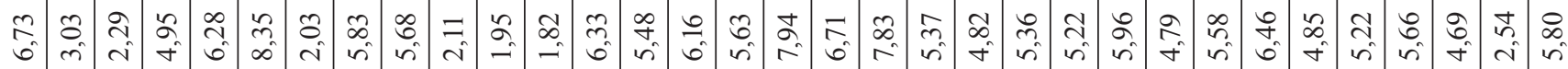

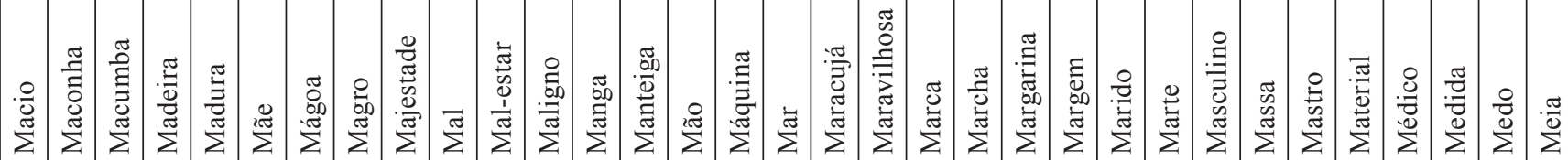

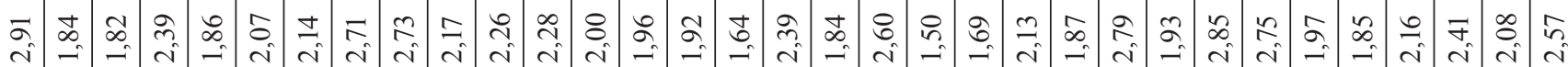

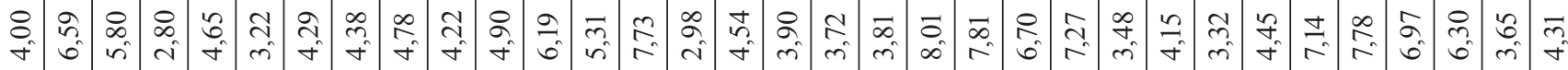

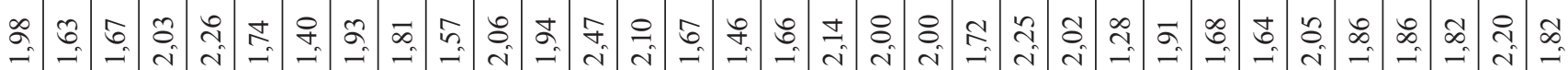

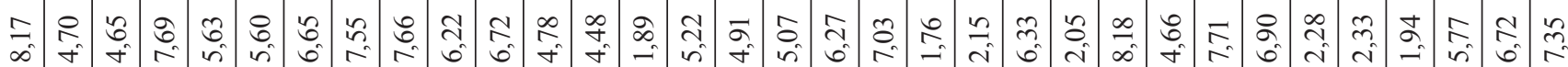

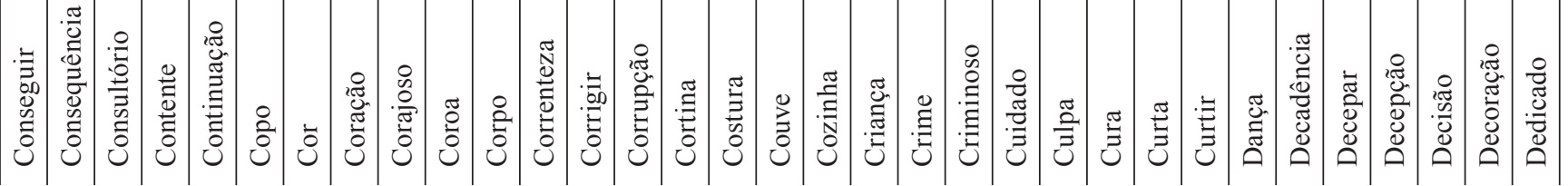




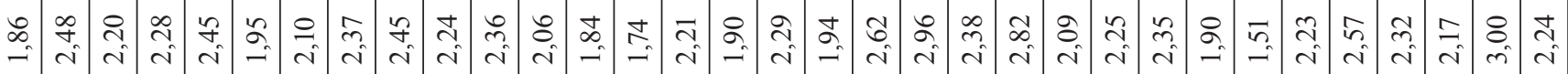

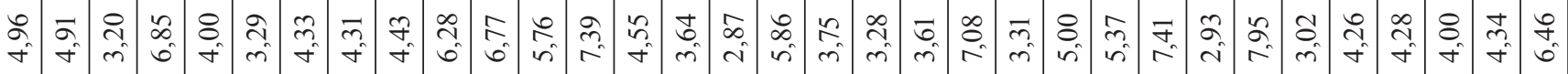

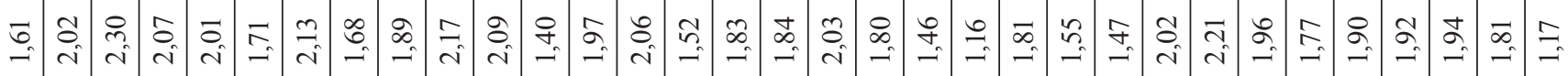

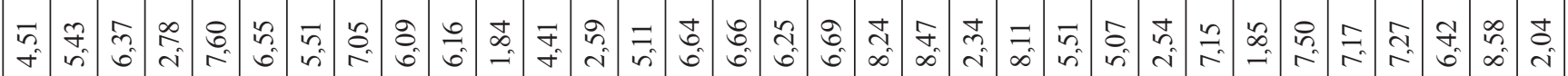

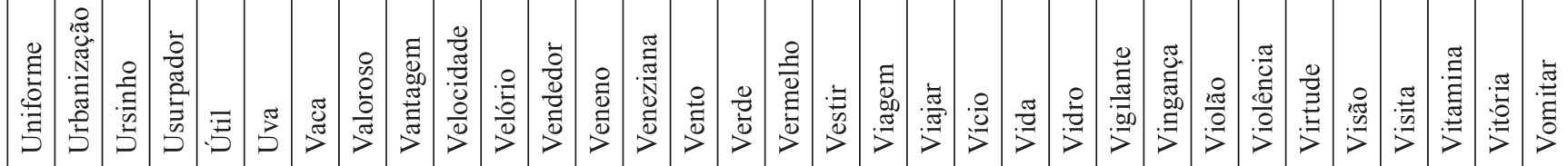

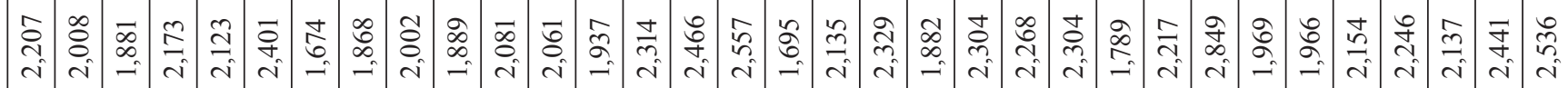

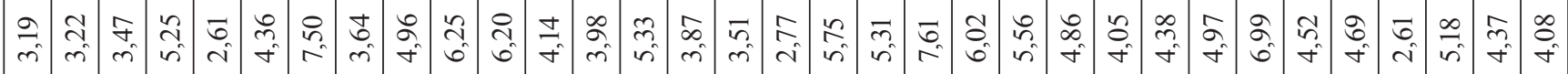

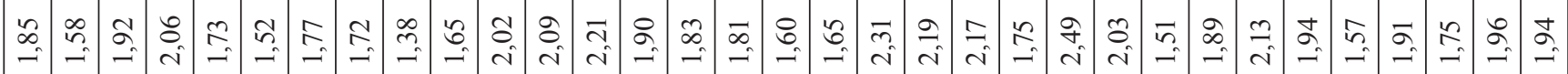

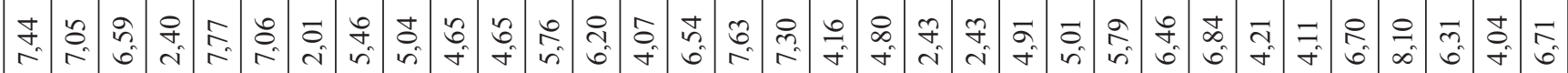

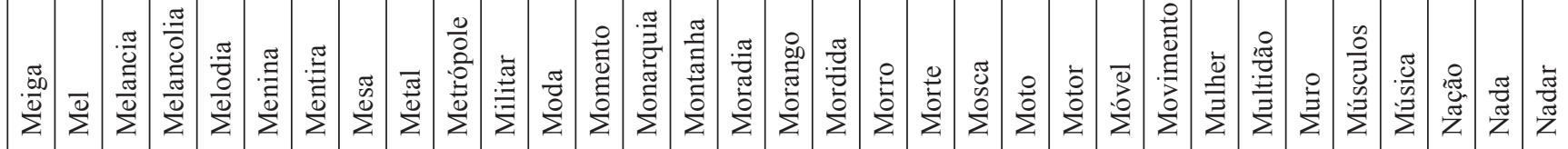

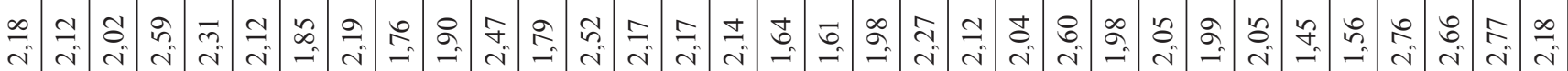

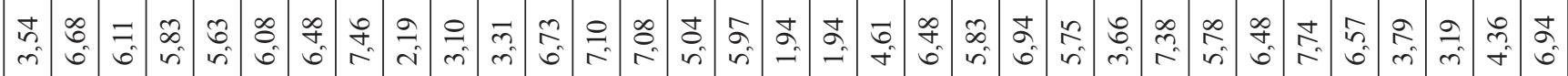

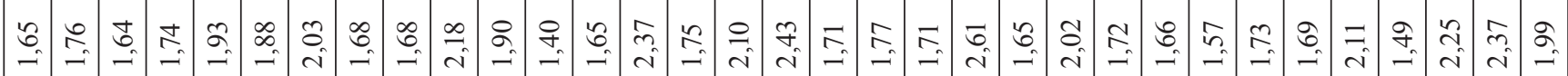

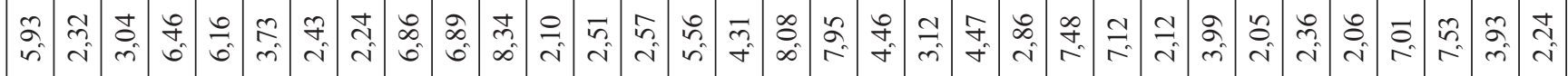

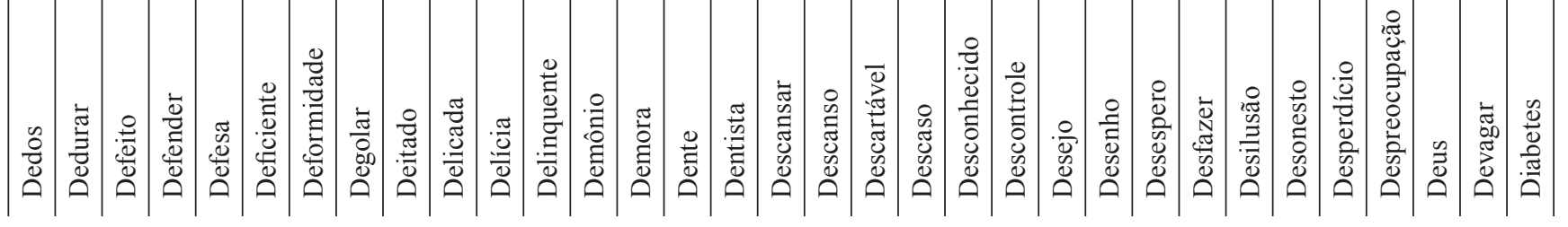




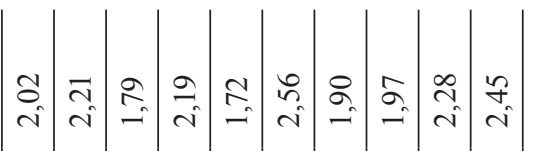

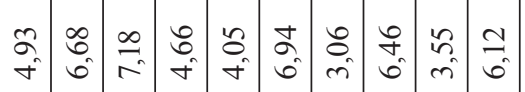

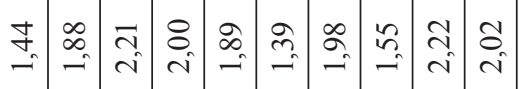

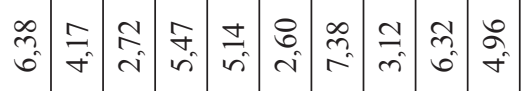

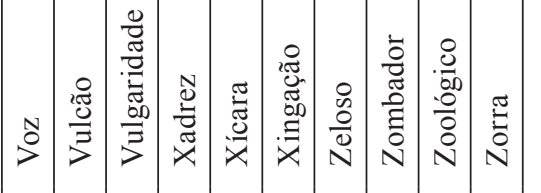

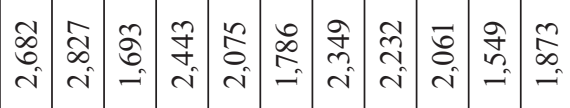

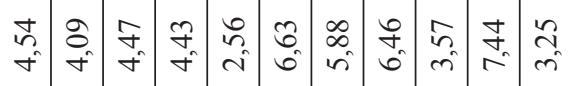

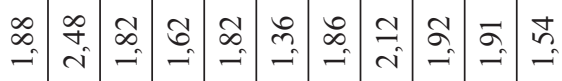

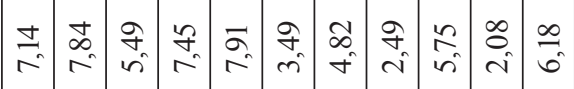

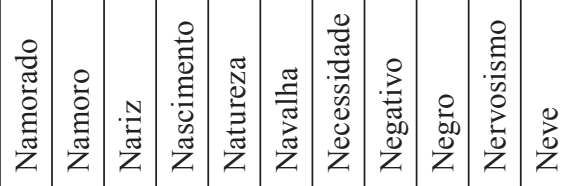

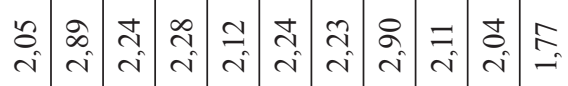

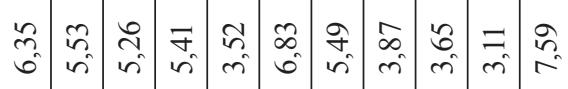

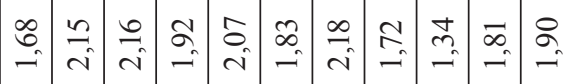

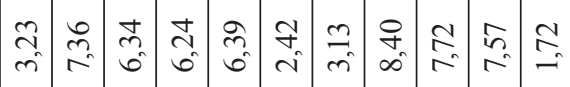

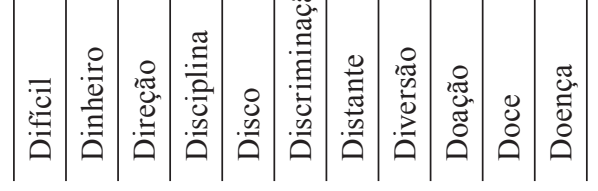

